\title{
Immunogold Staining of Ultrathin Thawed Cryosections for Transmission Electron Microscopy (TEM)
}

\author{
Jeremy N. Skepper and Janet M. Powell
}

This protocol was adapted from "Ultrastructural Immunochemistry," Chapter 7, in Immunohistochemistry: Methods Express (ed. Renshaw), from the Methods Express series. Scion Publishing Ltd., Oxfordshire, UK, 2006.

\section{INTRODUCTION}

A pre-embedding method of immunochemical staining is used if antigens are damaged by resin embedding, or if the best preservation of membranes is required. Applying immunogold reagents to sections of lightly fixed tissue, free of embedding medium, can be a very sensitive method of immunochemical staining. Cells or tissues are fixed as strongly as possible and then treated with a cryoprotectant, which is usually a mixture of sucrose and polyvinylpyrrolidone (PVP). They are frozen onto pins in liquid nitrogen and sectioned at approximately $-100^{\circ} \mathrm{C}$. The frozen sections are thaw-mounted on to Formvar/nickel film grids and the cryoprotectant is removed by floating the grids on drops of phosphate-buffered saline (PBS). The immunogold staining is performed on the unembedded sections, which are subsequently contrast counterstained and infiltrated with a mixture of methylcellulose and uranyl acetate. In this protocol, samples are sectioned at low temperature, thaw-mounted onto film grids, immunochemically stained, contrast counterstained, and embedded/encapsulated in situ on the grid before viewing by transmission electron microscopy (TEM).

\section{RELATED INFORMATION}

Ultrastructural Immunochemistry (Skepper and Powell 2008a) describes methods and considerations for the use of immunogold staining, including fixation, controls, resolution, and quantification. The following protocols provide detailed procedures for immunogold staining of various sections for TEM:

Immunogold Staining of Epoxy Resin Sections for Transmission Electron Microscopy (TEM) (Skepper and Powell 2008b)

Immunogold Staining of London Resin (LR) White Sections for Transmission Electron Microscopy (TEM) (Skepper and Powell 2008c)

Immunogold Staining Following Freeze Substitution and Low Temperature Embedding after Chemical Fixation or after Cryoimmobilization for Transmission Electron Microscopy (TEM) (Skepper and Powell 2008d)

For more comprehensive descriptions of the range of techniques available, see Griffiths et al. (1993) and Skepper (2000).

\section{MATERIALS}

CAUTIONS AND RECIPES: Please see Appendices for appropriate handling of materials marked with $<!>$, and recipes for reagents marked with $<\mathbf{R}>$. 


\section{Reagents}

$<\mathbf{R}>$ Antibodies, primary (optimally diluted in PBSG)

$<\mathbf{R}>$ Antibodies, secondary (optimally diluted in PBSG)

Use a secondary antibody raised against the species of the primary antibody and conjugated to 10- or 15-nm colloidal gold particles.

$<\mathbf{R}><$ ! $>$ Formaldehyde $(2 \% \mathrm{w} / \mathrm{v})$ (made from freshly depolymerized paraformaldehyde)

$<$ R $>$ Formaldehyde $(8 \%)$ in PIPES

Methylcellulose $(2 \%, \mathrm{w} / \mathrm{v})$

Methylcellulose is used in embedding media to reduce shrinkage, thus preventing the sections from collapsing totally during air-drying before viewing by TEM.

$<$ R $>$ PBSG

$<$ R $>$ PBS (1X) containing $10 \%(\mathrm{w} / \mathrm{v})$ gelatin

$<$ R $>$ Phosphate-buffered saline (PBS) $(\mathrm{pH} 7.6)$

PIPES buffer (0.1 M) ( $\mathrm{pH} 7.4)$

Sodium chloride $(0.9 \%, \mathrm{w} / \mathrm{v})$

Sucrose (1.9 M) and 10\% (w/v) polyvinylpyrrolidone (PVP-10)

Sucrose and PVP-10 are used as cryoprotectants.

Sucrose $(2.3 \mathrm{M})$

A 50:50 mixture of $2.3 \mathrm{M}$ sucrose and $2 \%$ methylcellulose is used as retrieval fluid; see Step 7.

Tissue (small pieces) or cells of interest

$<$ ! $>$ Uranyl acetate $(3 \%, \mathrm{w} / \mathrm{v}$; aqueous)

2\% methylcellulose and 3\% aqueous uranyl acetate are mixed in ratios varying from 9:1 to 5:1; see Step 13.

\section{Equipment}

\section{Cell scraper}

Diamond trim tool and $45^{\circ}$ ultradiamond knife (Diatome AG)

Eyelash (to maneuver sections)

Filter paper (hardened)

Frozen cryosection module (FCS) and cryo-prep center (CPC) freezing station (Leica

Microsystems)

$<$ ! $>$ Liquid nitrogen

Loop (copper, 1-mm diameter)

Micropipettor with tips

Microscope (transmission electron) (FEI Tecnai 120)

Nickel/Formvar grids (400 mesh)

Sectioning pins

Tubes (1.5-mL microcentrifuge)

Ultramicrotome (EM UCT; Leica Microsystems)

\section{METHOD}

\section{Tissue Preparation and Sectioning}

If it is possible to use strong fixation during tissue preparation (4\%-8\% formaldehyde for $2-4 \mathrm{~h}$ ), the preservation of cell membranes is excellent (Liou et al. 1996) (see Fig. 1). These sections can be stored on buffer at $4^{\circ} \mathrm{C}$ for several hours or even overnight, if more blocks are to be sectioned. However, caution should be exercised if the tissue has been fixed very lightly, because the ultrastructure will deteriorate as a function of the time that the section is floated on the buffer.

1. Rinse cells or small pieces of tissue twice in $0.9 \%$ sodium chloride.

2. Incubate cells or tissue pieces in formaldehyde (8\%) in PIPES for $1 \mathrm{~h}$ at $4^{\circ} \mathrm{C}$. If the cells are adherent, scrape them free from the substrate with a cell scraper and transfer to 1.5-mL tubes.

3. Rinse four times in 0.1 M PIPES buffer at room temperature over a period of 20 min and twice in $\mathrm{H}_{2} \mathrm{O}$. 


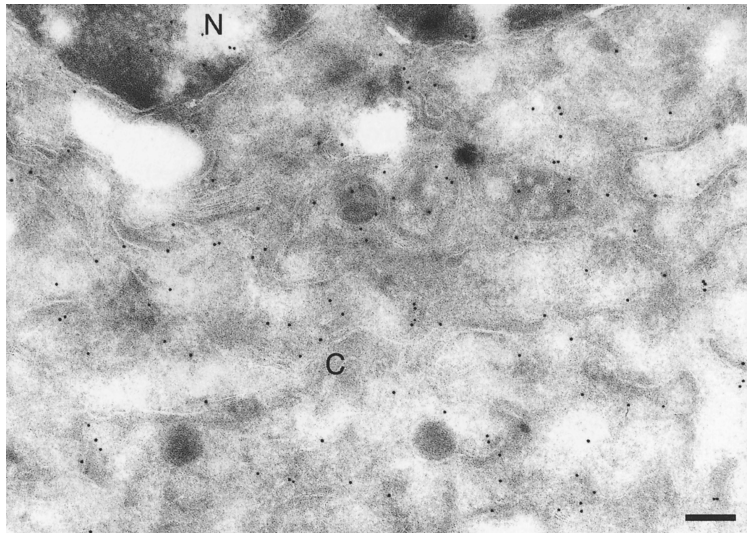

FIGURE 1. Ultrathin thawed cryosection of placental syncytium. Sections were fixed in $6 \%$ formaldehyde, cryoprotected in sucrose and PVP, and retrieved from the microtome on methylcellulose and sucrose. Cells were immunolabeled for copper/zinc superoxide dismutase. Gold particles can be seen over both the cytoplasm (C) and the nucleoplasm (N). Bar, $200 \mathrm{~nm}$. (Reprinted with permission from Scion Publishing Ltd. (C) 2006.)

4. Incubate in $1 \mathrm{X}$ PBS containing $10 \%$ gelatin for $2 \mathrm{~h}$ and centrifuge to form a pellet. Cool to $4^{\circ} \mathrm{C}$ and fix in $2 \%$ formaldehyde for $2 \mathrm{~h}$.

Small pieces of fixed tissue can be trimmed to $0.5 \mathrm{~mm}$ in one dimension.

5. Trim to $0.5-\mathrm{mm}^{3}$ cubes and incubate in $1.9 \mathrm{M}$ sucrose and $10 \%$ PVP-10 overnight at $4^{\circ} \mathrm{C}$.

6. Freeze the cubes onto sectioning pins in liquid nitrogen. Transfer to the frozen cryosection module (ultramicrotome with a cryochamber) at a temperature of between $-90^{\circ} \mathrm{C}$ and $-130^{\circ} \mathrm{C}$ and cut thin sections of $90-140 \mathrm{~nm}$.

See Troubleshooting.

7. Maneuver the sections away from the cutting edge of the knife with an eyelash. Place a drop of a 50:50 mixture of $2.3 \mathrm{M}$ sucrose and $2 \%$ methylcellulose in a 1-mm diameter copper loop and retrieve the sections from the frozen cryosection module. Allow the sucrose to thaw at room temperature and touch the sections onto the Formvar surface of a nickel/Formvar grid.

The droplet of retrieval fluid should be moved rapidly toward the sections, which will jump toward it and "disappear." The sucrose must remain liquid while the sections are retrieved or they will not fully decompress, so speed is critical.

\section{Tissue Staining}

Immunogold staining is carried out essentially the same as for resin sections with several modifications. The absence of an embedding medium means that many primary antibodies will bind strongly after $0.5-2 \mathrm{~h}$ exposure, so it is often convenient to use more dilute primary antibody solutions and stain immunochemically overnight. This conserves antibodies and tends to produce less nonspecific background staining.

8. Transfer sections to drops of PBSG.

9. Incubate sections on drops of optimally diluted primary antibody in PBSG at room temperature overnight.

10. Rinse sections on ten $100-\mu \mathrm{L}$ drops of $1 \mathrm{X}$ PBS, dispensed with a micropipettor, for 2 min on each drop.

11. Incubate sections on drops of optimally diluted species-specific secondary antibodies in PBSG (conjugated to 10- or 15-nm gold particles) at room temperature for $2 \mathrm{~h}$.

12. Rinse sections on ten $100-\mu \mathrm{L}$ drops of $1 \mathrm{X}$ PBS for 2 min on each drop.

13. Rinse briefly in $\mathrm{H}_{2} \mathrm{O}$ and incubate sections on drops of $2 \%$ methylcellulose and $3 \%$ aqueous uranyl acetate in ratios varying from 9:1 to 5:1, until the desired contrast is achieved. Blot away excess stain using hardened filter paper and air-dry sections before viewing at $80 \mathrm{kV}$ in a transmission electron microscope.

See Discussion. 


\section{TROUBLESHOOTING}

Problem: The sucrose tends to crumble.

[Step 6]

Solution: In tissues with voids such as blood vessels, the sucrose tends to crumble rather than section. This effect is particularly noticeable in fragile embryos. It can be prevented by filling the lumen of blood vessels with gelatin (Russell et al. 1998) or by infiltration of embryos with polyacrylamide gel (Tokuyasu 1983).

\section{DISCUSSION}

This technique for immunogold staining of lightly fixed, unembedded tissue is frequently referred to as the Tokuyasu technique (Tokuyasu 1973 ; 1983; 1986; 1989) after its pioneer. It is one of the few methods that is consistently used for immunochemical staining of sparse and labile membrane-bound proteins such as receptor molecules, and has been used to great advantage in the study of receptor internalization and endocytosis (Liou et al. 1997; Klumperman et al. 1998).

Small cubes of fixed tissue $\left(<0.25 \mathrm{~mm}^{3}\right)$ impregnated with either $2.3 \mathrm{M}$ sucrose (Tokuyasu 1986) or a mixture of 1.9-2.1 M sucrose and 10\% PVP as described here, to act as cryoprotectants (Tokuyasu 1989), are mounted on pins and frozen in liquid nitrogen. The high concentrations of cryoprotectant make rapid freezing unnecessary. Frozen sections can be retrieved on a drop of cold $2.3 \mathrm{M}$ sucrose, a mixture of sucrose and PVP, or more recently introduced alternative retrieval fluids, e.g., a 50:50 mixture of $2 \%$ methylcellulose and $2.3 \mathrm{M}$ sucrose (described here), or $1.5 \%-2 \%$ methylcellulose and 0.3\%-3\% uranyl acetate. Because the tissue has been fixed and sectioned directly after cryoprotection, residual reactive aldehyde groups may remain in the sections. These can be quenched by exposure to $0.1 \%-1 \%(\mathrm{w} / \mathrm{v})$ lysine or glycine in phosphate- or Tris-buffered saline for $10 \mathrm{~min}$.

After immunochemical staining, the sections are contrast counterstained and encapsulated in a matrix to prevent gross collapse of the sections caused by surface tension effects during subsequent air-drying. The most commonly used stain is uranyl acetate, which produces a negative contrast. Many variations and alternatives to uranyl acetate have been proposed, and are discussed in detail by Griffiths et al. (1993). Sections prepared as described in this protocol are stable for a considerable time. The thickness of the section and that of the final embedding layer influence the contrast in the transmission electron microscope. The thinnest, flattest sections produced with diamond knives produce the best contrast between the section and antibodies conjugated to small colloidal gold particles (5-20 nm) (Peters et al. 2003).

\section{REFERENCES}

Griffiths, G., Burke, B., and Lucocq, J. 1993. Fine structure immunocytochemistry. Springer-Verlag, Heidelberg, Germany.

Klumperman, J., Kuliawat, R., Griffith, J.M., Geuze, H.J., and Arvan, P. 1998. Mannose 6-phosphate receptors are sorted from immature secretory granules via adaptor protein AP-1, clathrin, and syntaxin 6-positive vesicles. J. Cell. Biol. 141: 359-371.

Liou, W., Geuze, H.J., and Slot, J.W. 1996. Improving structural integrity of cryosections for immunogold labeling. Histochem. Cell Biol. 106: 41-58.

Liou, W., Geuze, H.J., Geelen, M.J.H., and Slot, J.W. 1997. The autophagic and endocytic pathways converge at the nascent autophagic vacuoles. J. Cell. Biol. 136: 61-70.

Peters, P.J., Mironov Jr., A, Peretz, D., van Donselaar, E., Leclerc, E., Erpel, S., DeArmond, S.J., Burton, D.R., Williamson, R.A., Vey, M., et al. 2003. Trafficking of prion proteins through a caveolae-mediated endosomal pathway. J. Cell Biol. 162: 703-717.

Russell, F.D., Skepper, J.N., and Davenport, A.P. 1998. Human endothelial cell storage granules: A novel intracellular site for isoforms of the endothelin-converting enzyme. Circ. Res. 83: 314-321.

Skepper, J.N. 2000. Immunocytochemical strategies for electron microscopy: Choice or compromise. J. Microsc. 199: 1-36.
Skepper, J.N. and Powell, J.M. 2008a. Ultrastructural immunochemistry. CSH Protocols (this issue) doi: 10.1101/pdb.top47.

Skepper, J.N. and Powell, J.M. 2008b. Immunogold staining of epoxy resin sections for transmission electron microscopy (TEM). CSH Protocols (this issue) doi: 10.1101/pdb.prot5015.

Skepper, J.N. and Powell, J.M. 2008c. Immunogold staining of London Resin (LR) White sections for transmission electron microscopy (TEM). CSH Protocols (this issue) doi: 10.1101/ pdb.prot5016.

Skepper, J.N. and Powell, J.M. 2008d. Immunogold staining following freeze substitution and low temperature embedding after chemical fixation or after cryoimmobilization for transmission electron microscopy (TEM). CSH Protocols (this issue) doi: $10.1101 /$ pdb.prot5017.

Tokuyasu, K.T. 1973. A technique for ultracryotomy of cell suspensions and tissues. J. Cell. Biol. 57: 551-565.

Tokuyasu, K.T. 1983. Present state of immunocryoultramicrotomy. J. Histochem. Cytochem 31 (Suppl. 1A): 164-167.

Tokuyasu, K.T. 1986. Application of cryoultramicrotomy to immunocytochemistry. J. Microsc. 143: 139-149.

Tokuyasu, K.T. 1989. Use of poly(vinylpyrrolidone) and poly(vinyl alcohol) for cryoultramicrotomy. Histochem. J. 21: 163-171. 


\title{
Immunogold Staining of Ultrathin Thawed Cryosections for Transmission Electron Microscopy (TEM)
}

\author{
Jeremy N. Skepper and Janet M. Powell
}

Cold Spring Harb Protoc; doi: 10.1101/pdb.prot5018

\begin{tabular}{rc}
$\begin{array}{r}\text { Email Alerting } \\
\text { Service }\end{array}$ & Receive free email alerts when new articles cite this article - click here. \\
\hline $\begin{array}{c}\text { Subject } \\
\text { Categories }\end{array}$ & Browse articles on similar topics from Cold Spring Harbor Protocols. \\
& Antibodies, general (289 articles) \\
& Cell Biology, general (1382 articles) \\
& Cell Imaging (525 articles) \\
& Electron Microscopy (43 articles) \\
& Imaging/Microscopy, general (579 articles) \\
& Immunohistochemistry (92 articles) \\
& Immunoimaging (41 articles) \\
& Immunology, general (128 articles) \\
& Immunostaining (139 articles) \\
& Immunostaining Cells (51 articles) \\
& Labeling for Imaging (339 articles) \\
& Phenotypic Analysis (42 articles) \\
Visualization (524 articles) & Visualization of Gene Expression (127 articles) \\
Visualization of Organelles (88 articles) & \\
\hline
\end{tabular}

